Dr. Clouston, in acknowledging the honour conferred upon him, said that he was never so pleased with anything in his life. Being an Orcadian, bearing a name which is absolutely Orcadian, and a name found nowhere else but when borne by Orcadians and descendants of Orcadians, it was specially gratifying that he should be asked to receive the greatest honour which the Town Council of Kirkwall could confer on any citizen. There had been comparatively few men within the last hundred years who had received this great distinction, and so it was doubly welcome and doubly appreciated. Dr. Clouston referred to the work of his life, and indicated that statesmen should turn their attention to the sons of Orkney and Shetland to reinvigorate the race. Dr. Clouston then signed the Burgess Roll, and was afterwards entertained to a banquet in the Kirkwall Hotel, where the proceedings were enthusiastic and cordial. We feel sure that $\mathrm{Dr}$. Clouston's many friends will compliment him upon this new honour which has been so kindly conferred upon him. They best know how well deserved it was. We need only add our congratulations to Dr. Clouston, and express our best wishes.

\title{
DR. MAGNAN
}

Dr. Magnan's jubilee has been honoured in Paris by a concourse of distinguished friends. For forty years he has been physician to the admission block of St. Anne's Asylum, and his former fellow-student, Dr. Bouchard, presided at the festival. Dr. Magnan was presented with a beautiful plaque, the work of Professor Richer of the Institute; and the subscribers are to receive replicas in the form of medals. Well-known colleagues were present, Dr. Ritti, representing the MedicoPsychological Society ; Drs. Briand and Sérieux, speaking in the name of former pupils ; Dr. Ladame for Switzerland ; and Dr. Bagenof for Russia. Dr. Mierzejewsky had been chosen by his friends to represent them, had journeyed to Paris for the purpose, but the calamity of his sudden and fatal disease occurred on the very day of the ceremony.

Dr. Sérieux said, My dear master, observer, investigator, incomparable clinician, you have upheld the glorious traditions of French psychiatry, and it is to you we owe the present position of our branch of medicine. We cannot forget that you are also a teacher and the benefactor of your patients. I hardly see anyone here who has not been your pupil, directly or indirectly. Teacher you certainly are, not only by way of formulz, but also by your good deeds and the thorough performance of your daily duty. Devoted to duty not only in the advancement of science but also in the care of your patients-finding words of comfort for them and combatting the coalition of routine with ignorance-we find to have been an education of the best. We have not only had our preference for mental pathology developed, but have found it revivified by your published works. Your influence has permeated France, and spread throughout the world where your pupils are scattered. Your life has been a valuable lesson on which to meditateune excitation à bien penser et à bien faire. You have lived among your patients, disdaining publicity, taking no account of popularity, which some so often use to conquer. You require much of your colleagues, but are still more exacting of yourself. I have seen you late at night calming one patient and comforting another. I have heard them pour forth their troubles to you while I was lost in admiration. Your ardour is unabated after forty years of work here. Here is your life and the unity of it is splendid. Without your personal influence what prejudices would yet live, how many unfortunate patients would yet wear straitwaistcoasts in absolute isolation? We bow to-day before the master and benefactor.

\section{CONOLLY NORMAN MEMORIAL FUND.}

Thr Honorary Treasurers of this Fund will be greatly obliged if all intending subscribers will forward their contributions at an early date. 